\title{
Biological activities of Portuguese propolis: Protection against free radical-induced erythrocyte damage and inhibition of human renal cancer cell growth in vitro
}

\author{
Maria J. Valente ${ }^{\mathrm{a}}$, Ana F. Baltazar ${ }^{\mathrm{b}}$, Rui Henrique ${ }^{\mathrm{c}, \mathrm{d}}$, Letícia Estevinho ${ }^{\mathrm{e}}$, Márcia Carvalho ${ }^{\mathrm{a}, \mathrm{b}, *}$ \\ ${ }^{a}$ REQUIMTE, Toxicology Department, Faculty of Pharmacy, University of Porto, Porto, Portugal \\ ${ }^{\mathrm{b}}$ CEBIMED/Research Group on Toxicology and Phytochemistry, Faculty of Health Sciences, University Fernando Pessoa, Porto, Portugal \\ ${ }^{\mathrm{c}}$ Department of Pathology and Cancer Epigenetics Group - Research Center, Portuguese Oncology Institute-Porto, Porto, Portugal \\ ${ }^{\mathrm{d}}$ Department of Pathology and Molecular Immunology, Institute of Biomedical Sciences Abel Salazar (ICBAS), University of Porto, Portugal \\ e CIMO, Escola Superior Agrária, Instituto Politécnico de Bragança, Bragança, Portugal
}

\section{A R T I C L E I N F O}

\section{Article history:}

Received 23 June 2010

Accepted 2 October 2010

\section{Keywords:}

Portuguese propolis

Antioxidant activity

Erythrocyte

Renal cell carcinoma

Antiproliferative activity

Cancer chemoprevention

\begin{abstract}
A B S T R A C T
This study reports for the first time the biological properties of Portuguese propolis. The antioxidant potential of propolis samples from Bornes (Northeast) and Fundão (Centre) regions of Portugal was evaluated by their ability to inhibit the $2,2^{\prime}$-azobis(2-amidinopropane) dihydrochloride (AAPH)-induced oxidative hemolysis and lipid peroxidation in human erythrocytes. Bornes and Fundão propolis strongly protected the erythrocyte membrane from hemolysis ( $\mathrm{IC}_{50}$ of $6.3 \pm 0.7$ and $10.4 \pm 2.7 \mu \mathrm{g} / \mathrm{ml}$, respectively), in a time- and concentration-dependent manner. This effect was found to be significantly higher than that presented by ascorbic acid $\left(\mathrm{IC}_{50}\right.$ of $\left.31.0 \pm 5.6 \mu \mathrm{g} / \mathrm{ml}\right)$. In addition, human erythrocytes treated with propolis extracts showed concentration-dependent decrease in levels of malondialdehyde, a breakdown product of lipid peroxidation. Propolis extracts were also assayed for their anticancer properties on human renal cell carcinoma (RCC). Primary cultures of normal and cancerous renal cells derived from RCC patients, in addition to A-498 cell line, were treated with propolis extracts $(0-100 \mu \mathrm{g} / \mathrm{ml})$. Cytotoxic and antiproliferative effects were determined by the 3-(4,5-dimethylthiazol-2-yl)-2,5-diphenyltetrazolium bromide (MTT) assay. Propolis extracts exhibited selective toxicity against malignant cells compared to normal cells. In vitro RCC growth was strongly inhibited by Bornes and Fundão propolis in a concentration-dependent manner. Our results indicate that Portuguese propolis constitutes an excellent source of effective natural antioxidant and chemopreventive agents.
\end{abstract}

(c) 2010 Elsevier Ltd. All rights reserved.

\section{Introduction}

Propolis is a complex resinous bee product widely employed in traditional medicine owed to its plethora of biological activities. Many in vitro studies have already confirmed its antibacterial (Scazzocchio et al., 2006), antifungal (Silici et al., 2005), antiviral (Schnitzler et al., 2010), antiinflammatory (Tan-No et al., 2006), antioxidant (Banskota et al., 2000), hepatoprotective (Banskota et al., 2001a), cariostatic (Libério et al., 2009), anticancer (Russo et al., 2004; Orsolić et al., 2006), and immunostimulant (Sforcin, 2007) properties. Therefore, propolis has attracted much attention in recent years as a useful or potential agent with application in pharmaceutical products and in the food industry for health foods, beverages and nutritional supplements. Propolis composition is

* Corresponding author. Adderss: Faculdade de Ciências da Saúde, Universidade Fernando Pessoa, R. Carlos da Maia, 296, 4200-150 Porto, Portugal. Tel.: +351 225074630; fax: +351 225508269 .

E-mail address: mcarv@ufp.edu.pt (M. Carvalho). very complex. It contains mainly waxes, resin and volatiles. The main chemical groups present in propolis resin comprise phenolic acids or their esters, flavonoids (flavones, flavanones, flavonols, dihydroflavonols and chalcones), terpenes, aromatic aldehydes and alcohols, fatty acids, stilbenes and $\beta$-steroids (Marcucci, 1995; Gardana et al., 2007). Biological and therapeutic actions of propolis are generally attributed to its constituents of plant origin, mainly phenolics (Burdock, 1998). In the present study, we report for the first time the biological actions of Portuguese propolis, specifically its antioxidant and antiproliferative activities.

Flavonoids represent the main group of chemical compounds present in the European propolis samples and are well-known to possess antioxidant activity, mainly via their free radical scavenging activity and metal chelating properties (Perron and Brumaghim, 2009; Rice-Evans, 2001; Cao et al., 1997). Many studies have already shown strong antioxidant properties for different propolis samples using different chemical assays, such as scavenging of DPPH radical (Izuta et al., 2009; Moreira et al., 2008; Banskota et al., 2000), scavenging of superoxide anion (Russo et al., 2004), 
$\beta$-carotene bleaching assay (Kumazawa et al., 2004), and inhibition of DNA cleavage induced by hydrogen peroxide UV-photolysis (Russo et al., 2004). Nevertheless, the validation of this effect in human cell-based model assays is extremely important. Therefore, the in vitro oxidative damage of human erythrocytes was used in this study as a model to evaluate the free radical-induced damage of biological membranes and the protection conferred by the propolis extracts. AAPH was used herein as source of peroxyl radicals to initiate lipid peroxidation and subsequent hemolysis. As far as we know, this is the first study concerning the antihemolytic activity of propolis extracts on human erythrocytes.

Moreover, an important point in propolis research refers to its anticancer properties. Propolis and its phenolic compounds have been demonstrated to exert protective effect against several types of cancer, including colon (Banskota et al., 2002; Ishihara et al., 2009; Usia et al., 2002), pancreatic (Li et al., 2010; Awale et al., 2008), cervical (Sha et al., 2009), skin (Chen et al., 2004), and lung (Weng et al., 2007; Li et al., 2008), among others. Several mechanisms contribute to the overall cancer preventive and antitumor properties of propolis and its phenolic components, including cell-cycle arrest, induction of apoptosis, and inhibition of cancer cells proliferation and tumor growth (Orsolić et al., 2006; Chen et al., 2004; Bufalo et al., 2010; Fresco et al., 2006). Although anticancer properties of propolis have been shown in several cancer types, its effect in renal cell carcinoma (RCC) is hitherto unknown. Therefore, in this study, the antiproliferative activity of propolis extracts on primary cultured cancerous renal cells (derived from patients with kidney cancer) and A-498 cell line was evaluated. In order to determine whether the extracts exhibit a selective cytotoxic effect against cancer cells, an 3-(4,5-dimethylthiazol-2-yl)2,5-diphenyltetrazolium bromide (MTT) based cytotoxic assay was carried out using normal renal cells. To our knowledge, this is the first time that the potential use of propolis extracts in chemoprevention of RCC is evaluated.

\section{Materials and methods}

\subsection{Chemicals}

2,2'-Azobis(2-amidinopropane) dihydrochloride (AAPH), trichloroacetic acid (TCA), 1,1,3,3-tetraethoxypropane (TEP), thiobarbituric acid (TBA), butylated hydroxytoluene (BHT), and MTT were purchased from Sigma (St. Louis, MO). Dulbecco's modified Eagle's medium nutrient mixture F12 Ham (DMEM/F12) GlutaMax $^{\mathrm{TM}}$-I, RPMI 1640 GlutaMax $^{\mathrm{TM}}$-I medium, heat-inactivated fetal bovine serum (FBS), penicillin-streptomycin, fungizone, human transferring, and trypsin-EDTA were purchased from Gibco-Invitrogen. All other chemicals were of analytical grade and obtained from Sigma (St. Louis, MO).

\subsection{Samples}

Propolis samples were collected by beekeepers in September 2007 from Apis mellifera hives located in Serra de Bornes in the Northeast of Portugal and in Fundão (Beira Interior region) in the Centre of Portugal. These propolis samples were frozen at $-20^{\circ} \mathrm{C}$ until analysis.

\subsection{Extraction procedure}

Samples were prepared by mixing propolis with methanol $(1: 1, v / v)$ and left over-night in agitation (200 rpm) at room temperature. The obtained solution was filtered (Whatman $\mathrm{n} 4$ filter paper) and the residue was re-extracted twice more under the same conditions. Combined methanolic extracts were then placed at low temperatures and, after $12 \mathrm{~h}$, filtered to remove wax and evaporated to dryness. The extraction yields in relation to dry matter were $49 \%$ and $53 \%$ for Bornes and Fundão samples, respectively.

\subsection{Antioxidant activity assessment}

\subsubsection{Preparation of human erythrocyte suspensions}

Blood (5-10 ml) was obtained from healthy non-smoker adult individuals after informed consent. Human erythrocytes from citrated blood were immediately isolated by centrifugation at $1500 \mathrm{rpm}$ for $10 \mathrm{~min}$ at $4{ }^{\circ} \mathrm{C}$. After removal of plasma and buffy coat, the erythrocytes were washed three times with phosphate-buffered saline (PBS; $\mathrm{pH} 7.4$ ) at $4{ }^{\circ} \mathrm{C}$, and, finally, resuspended in PBS to obtain erythrocyte suspensions at $2 \%$ or $5.2 \%$ hematocrit.

\subsubsection{Inhibitory efficiency of propolis extracts on AAPH-induced lipid peroxidation}

Bornes and Fundão propolis extracts were initially solubilized in an amount of dimethylsulfoxide (DMSO) to obtain $50 \mathrm{mg}$ extract/ml stock solutions and further diluted in PBS to obtain final concentrations of 5, 10, and $20 \mu \mathrm{g}$ extract $/ \mathrm{ml}$ for Bornes propolis and 10, 20 and $40 \mu \mathrm{g}$ extract/ml for Fundão propolis. From these serial dilutions, the DMSO final concentration was never higher than $0.08 \%$. In order to induce free-radical chain oxidation in erythrocytes, aqueous peroxyl radicals were generated by thermal decomposition of AAPH (final concentration of $50 \mathrm{mM}$ in PBS). To study the protective effects of propolis extracts against AAPH-induced lipid peroxidation, an erythrocyte suspension at $5.2 \%$ hematocrit was preincubated with the extracts of Bornes or Fundão propolis at $37^{\circ} \mathrm{C}$ for $30 \mathrm{~min}$, followed by incubation with and without $50 \mathrm{mM}$ AAPH. The extention of lipid peroxidation was estimated by HPLC-UV quantification of malondialdehyde (MDA), as previously described (Soares et al., 2004). Briefly, $250 \mu$ l of erythrocyte suspensions were taken at time $3 \mathrm{~h}$ and added to $25 \mu \mathrm{l}$ of $0.2 \%$ BHT (in order to prevent further lipid peroxidation) and $1 \mathrm{ml}$ of $1 \%$ TCA. The samples were then vortexed, centrifuged $\left(10,000 \mathrm{rpm}\right.$ for $10 \mathrm{~min}$, at $\left.4{ }^{\circ} \mathrm{C}\right)$, and $500 \mu \mathrm{l}$ of $1 \%$ TBA was added to equal volume of supernatant layer and allowed to stand at $95{ }^{\circ} \mathrm{C}$ during $45 \mathrm{~min}$. After cooling at $4{ }^{\circ} \mathrm{C}$, the samples were vortexed briefly, centrifuged, and $50 \mu \mathrm{l}$ of supernatants were injected on a HPLC system equipped with UV detector (Hewlett Packard 1100 series) set at $532 \mathrm{~nm}$. Chromatographic separation was carried out using a Waters Spherisorb C18, $5 \mu \mathrm{m}$ ODS2 $(4.6 \times 250 \mathrm{~mm}$ analytical cartridge $)$ from Waters Corporation. The mobile phase consisted of methanol: ammonium acetate buffer $0.05 \mathrm{M}$ ( $\mathrm{pH} 5.5$ ), at a solvent flow rate of $0.7 \mathrm{ml} / \mathrm{min}$. TEP standards in a concentration range $0.25-10 \mu \mathrm{M}$ were used to obtain the standard curve calibration and the results were expressed as $\mu \mathrm{M}$ MDA equivalents. The $50 \%$ inhibitory concentration $\left(\mathrm{IC}_{50}\right)$ was calculated from concentration-response curve obtained by plotting the percentage of lipid peroxidation inhibition versus the extract concentration. Inhibition percentage values were calculated considering as $100 \%$ the value of lipid peroxidation induced by AAPH in the absence of the extracts. Three independent experiments were used for these calculations.

\subsubsection{Protective effect of propolis extracts on AAPH-induced hemolysis}

The assays were performed using an erythrocyte suspension at $2 \%$ hematocrit. The cells were preincubated at $37^{\circ} \mathrm{C}$ for $30 \mathrm{~min}$ in the presence of the chosen concentrations of Bornes $(5-20 \mu \mathrm{g}$ extract $/ \mathrm{ml})$ or Fundão propolis $(10-40 \mu \mathrm{g}$ extract/ $\mathrm{ml}$ ), and then $50 \mathrm{mM}$ AAPH solution was added. This reaction mixture was shaken gently while being incubated at $37^{\circ} \mathrm{C}$ for $4 \mathrm{~h}$. In all experiments, a negative control (erythrocytes in PBS), as well as extract controls (erythrocytes in PBS with each extract) were used.

The extent of hemolysis was determined spectrophotometrically according to a method reported before (Ko et al., 1997). Briefly, aliquots of the reaction mixture were taken out at each hour of the $4 \mathrm{~h}$ of incubation, diluted with saline, and centrifuged at $4000 \mathrm{rpm}$ for $10 \mathrm{~min}$ to separate the erythrocytes. The percentage of hemolysis was determined by measuring the absorbance of the supernatant (A) at $545 \mathrm{~nm}$ and compared with that of complete hemolysis (B) by treating an aliquot with the same volume of the reaction mixture with distilled water. The hemolysis percentage was calculated using the formula: $A / B \times 100$. $\mathrm{IC}_{50}$ values at time $3 \mathrm{~h}$ were also determined from concentration-response curve obtained by plotting the percentage of hemolysis inhibition versus the extract concentration. Ascorbic acid was used as the reference antioxidant compound. Four independent experiments were used for these calculations.

\subsection{Antitumoral activity assessment}

\subsubsection{Isolation and primary cultures of normal and cancerous renal cells}

Human kidney tissue samples were obtained from consenting patients undergoing radical nephrectomy for renal cell carcinoma at the Portuguese Oncology Institute-Porto. Tissue samples were collected from areas defined as normal (in the cortex) or tumoral by an expert uropathologist. Renal cell isolation took place immediately after sample collection as previously described by Carvalho et al. (2002) with some modifications. Briefly, after removing the renal capsule, tissue was minced finely and then submitted to $1 \mathrm{mg} / \mathrm{ml}$ collagenase (type II) digestion. Isolated renal cells were subsequently purified by sequential filtration through 100, 70 and $40 \mu \mathrm{m}$ sieves. Renal cells were then seeded in culture flasks $\left(5 \times 10^{4}\right.$ cells $\left./ \mathrm{cm}^{2}\right)$ and incubated at $37{ }^{\circ} \mathrm{C}$ in a humidified incubator with $5 \% \mathrm{CO}_{2}$. The culture medium was DMEM/F12 supplemented with $10 \% \mathrm{FBS}, 50 \mu \mathrm{g} / \mathrm{ml}$ penicillin-streptomycin, $2.5 \mu \mathrm{g} / \mathrm{ml}$ fungizone, and $5 \mu \mathrm{g} / \mathrm{ml}$ human transferrin. Culture medium was changed after $24 \mathrm{~h}$ and every $48 \mathrm{~h}$ thereafter. All cells were studied after no more than three passages.

\subsubsection{A-498 cell line}

Human renal epithelial cancer cells A-498 (ATCC HTB-44) were cultured in RPMI 1640 medium GlutaMax ${ }^{\mathrm{TM}}$ with $25 \mathrm{mM}$ N-2-hydroxyethylpiperazine-NO-2ethanesulfonic acid (HEPES) containing $10 \% \mathrm{FBS}, 100 \mu \mathrm{g} / \mathrm{ml}$ penicillin-streptomy- 
cin, and $5 \mu \mathrm{g} / \mathrm{ml}$ human transferrin. Cells were grown in culture flasks $\left(5 \times 10^{4}\right.$ cells $\left./ \mathrm{cm}^{2}\right)$ in a humidified incubator at $37^{\circ} \mathrm{C}$ with an atmosphere of $5 \% \mathrm{CO}_{2}$.

2.5.3. Cytotoxicity of propolis extracts in primary cultured normal renal cells

Primary normal renal cells were subcultured at $5 \times 10^{3}$ cells per well on 96-well plates at $37{ }^{\circ} \mathrm{C}$ in a humidified atmosphere containing $5 \% \mathrm{CO}_{2}$. As judged by light microscopy, monolayers reached confluency 4-5 days after plating. The cells were then incubated for $24 \mathrm{~h}$ with different concentrations of Fundão and Bornes propolis. Each extract was initially solubilized in an amount of absolute ethanol to obtain $20 \mathrm{mg}$ extract $/ \mathrm{ml}$ stock solutions and further diluted in medium to obtain final concentrations of $100,50,25$, and $10 \mu \mathrm{g}$ of extract/ml. From these serial dilutions, the ethanol final concentration was never higher than $0.5 \%$ and the same concentration was used for solvent-control wells. Cell viability was measured using the mitochondrial MTT assay. MTT is a yellow water-soluble dye that is reduced in viable cells to an insoluble purple coloured product, MTT-formazan by the mitochondrial enzyme succinate dehydrogenase. At the end of exposure time, the medium was removed and the cells were washed once with fresh culture medium. Subsequently the cultures were incubated at $37{ }^{\circ} \mathrm{C}$ in a humidified atmosphere containing $5 \% \mathrm{CO}_{2}$ for $1 \mathrm{~h}$ with $200 \mu \mathrm{l}$ of $0.5 \mathrm{mg} / \mathrm{ml}$ MTT (final concentration). MTT solution was then removed and formazan contained in cells was solubilized with $100 \mu$ DMSO. The extent of reduction of MTT to formazan was quantified through the measurement of absorbance at $550 \mathrm{~nm}$ in a microplate reader. Cell viability was measured as the percentage of absorbance compared to control. Data are expressed as mean \pm SEM of three independent experiments performed in quadruplicate.

\subsubsection{Growth inhibitory activity of propolis extracts in cancerous renal cells}

Primary cultures of human cancerous renal cells and A-498 cancer cell line were used to study the antiproliferative properties of propolis extracts on RCC cells. After trypsin detachment, cells were counted, subcultured at $5 \times 10^{3}$ cells per well on 96-well plates, and incubated at $37{ }^{\circ} \mathrm{C}$ in a $5 \% \mathrm{CO}_{2}$ environment to allow for cell attachment. After $24 \mathrm{~h}$ of incubation, exponentially growing cells were treated with Bornes or Fundão propolis extracts at final concentrations of $10,25,50$, or $100 \mu \mathrm{g} /$ $\mathrm{ml}$. The plates were incubated for $48 \mathrm{~h}$ under the same conditions. At the end of the exposure time, the antiproliferative activity of propolis extracts on the cancerous cells was measured by evaluating cell viability using the MTT colorimetric assay, as previously described. $\mathrm{IC}_{50}$ values, defined as the amount of extract that inhibits $50 \%$ of cell growth, were calculated after $48 \mathrm{~h}$ of incubation from concentration-response curves obtained by plotting the percentage of growth inhibition versus the extract concentration. Data are expressed as mean \pm SEM of three independent experiments performed in quadruplicate.

\subsection{Statistical analysis}

Statistic analysis was performed using the Statistical Package for Social Sciences (SPSS, version 16.0) for Windows. Comparisons between two groups were performed by unpaired $t$-test. Multiple comparisons between more than two groups were performed by one-way ANOVA supplemented with Tukey's HSD post hoc test. Significance was accepted at $P$ lower than 0.05 .

\section{Results and discussion}

\subsection{Portuguese propolis protects the human erythrocyte against free radical damage}

The erythrocyte membrane is rich in polyunsaturated fatty acids that are highly susceptible to free radical-mediated peroxidation. The addition of AAPH, a peroxyl radical (ROO') initiator, to erythrocytes causes oxidation of lipids and proteins in cell membrane and thereby induces hemolysis (Zou et al., 2001). Inhibition of lipid peroxidation by antioxidant compounds is a very important way by which they can mitigate the induction and/or propagation of oxidative stress related diseases. Therefore, the AAPH-induced oxidative damage on human erythrocytes provides a good experimental model to evaluate the biological relevance of the antioxidant activity of several compounds (Zou et al., 2001; Costa et al., 2009; Carvalho et al., 2010).

In this study, the antioxidant properties of extracts from Portuguese propolis were initially evaluated by their efficacy to inhibit AAPH-induced peroxidation to erythrocyte membrane lipids. The extent of lipid peroxidation was assessed by measuring the formation of MDA, a well-known carbonyl product of oxidative lipid damage (Esterbauer et al., 1991). As shown in Fig. 1, the MDA levels in the erythrocytes of the control group was low

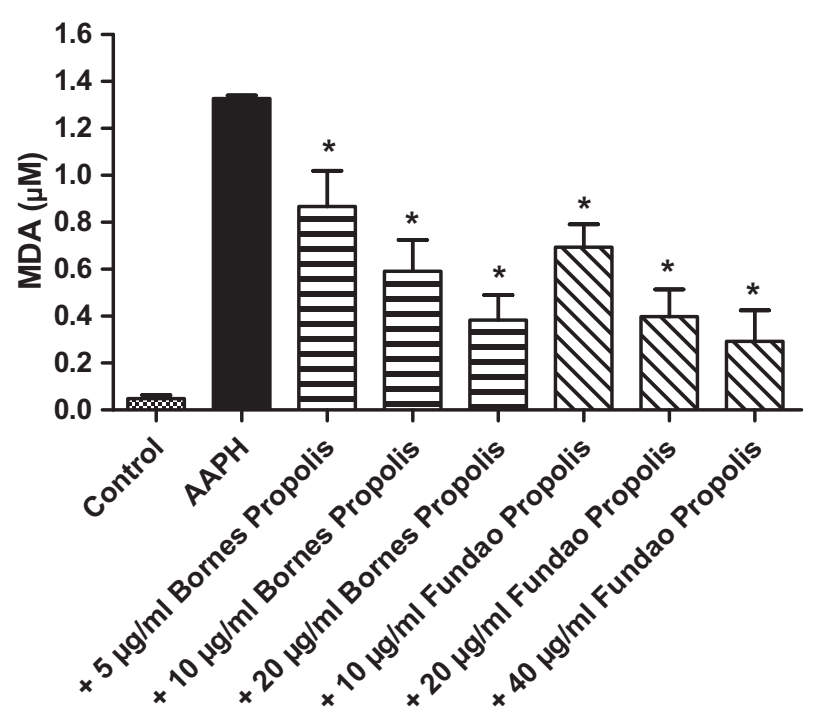

Fig. 1. Effect of propolis extracts from Bornes and Fundão regions on AAPH-induced lipid peroxidation. Erythrocyte suspension at $5.2 \%$ hematocrit was incubated with PBS (control) or preincubated with the extracts at the indicated concentrations for $30 \mathrm{~min}$ at $37^{\circ} \mathrm{C}$. The cell suspension was then incubated with $50 \mathrm{mM}$ AAPH for $3 \mathrm{~h}$ at $37^{\circ} \mathrm{C}$. Values are expressed as mean \pm SD of four independent experiments. *Represents significant results $(P<0.05)$ when the treated group was compared with the AAPH group.

$(0.049 \pm 0.014 \mu \mathrm{M})$ at $3 \mathrm{~h}$. When the erythrocytes were incubated with propolis extracts in the absence of AAPH, MDA formation was maintained at a background level similar to that of the control group (AAPH untreated samples) (data not shown). As expected, MDA level significantly increased (by $2608 \%$ at $3 \mathrm{~h}$ ) after incubation with $50 \mathrm{mM}$ AAPH when compared to the respective control. Under the oxidative action of AAPH, human erythrocytes treated with propolis extracts significantly decreased the AAPH effect $(P<0.05)$ in a concentration-dependent manner. Treatment with Bornes and Fundão propolis at the highest concentration for $3 \mathrm{~h}$ reduced MDA levels by $71 \%$ and $78 \%$, respectively, over the AAPHtreated cells. The $\mathrm{IC}_{50}$ values, defined as the amount of extract that inhibits $50 \%$ of AAPH-induced lipid peroxidation, were respectively $8.1 \pm 2.3$ and $9.7 \pm 2.3 \mu \mathrm{g}$ of extract/ml for Bornes and Fundão propolis.

Peroxidation to membrane lipids (by disturbing the structural lipid bilayer) may alter the membrane permeability and disrupts ionic channels. Hence, the antioxidant effects of propolis extracts in the erythrocyte membrane were also evaluated by the protection conferred by these extracts against hemolysis induced by AAPH. Fig. 2 shows the AAPH-induced hemolysis in human erythrocytes and the protective effects of Portuguese propolis extracts. Erythrocytes incubated at $37^{\circ} \mathrm{C}$ as a $2 \%$ suspension in PBS were stable with little hemolysis observed within $4 \mathrm{~h}(3.7 \pm 1.5 \%)$. When AAPH was added to the suspension of erythrocytes, hemolysis induction was time-dependent. The hemolysis is lagged, indicating that endogenous antioxidants in the erythrocytes, namely glutathione, tocopherol, ascorbate and enzymes, such as catalase and superoxide dismutase, can efficiently quench radicals to protect them against free radical-induced hemolysis, as described previously (Zou et al., 2001). Bornes and Fundão propolis significantly protected the erythrocyte membrane from hemolysis induced by $\mathrm{AAPH}$ in a concentration- and time-dependent manner (Fig. 2A and $B$, respectively), with $\mathrm{IC}_{50}$ values after $3 \mathrm{~h}$ of incubation of $6.3 \pm 0.7$ and $10.4 \pm 2.7 \mu \mathrm{g}$ of extract $/ \mathrm{ml}$, respectively. When the cells were incubated with either $0.08 \%$ DMSO or the highest tested concentration of each propolis extract in the absence of AAPH, hemolysis was maintained at a background level similar to that 

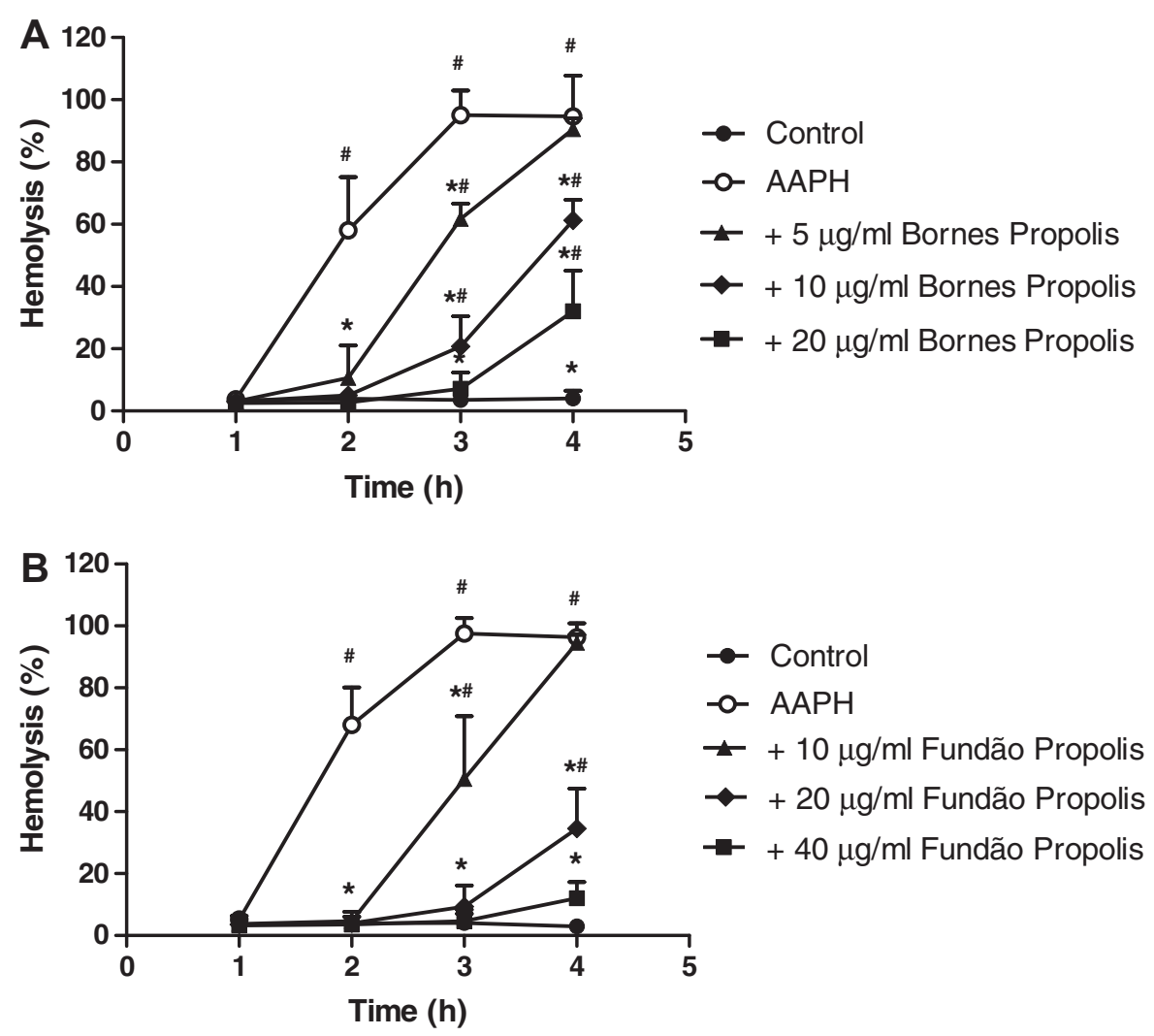

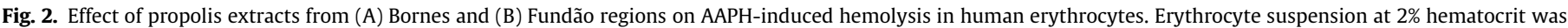

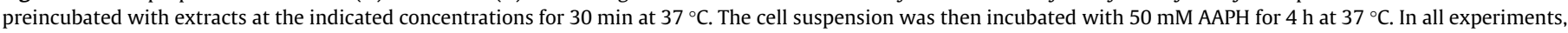

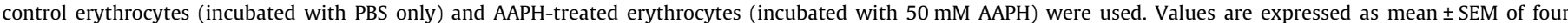

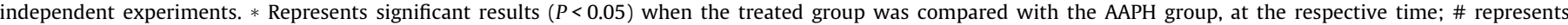
significant results $(P<0.05)$ when the treated group was compared with the control group, at the respective time.

in the control samples (data not shown). In this study, the antihemolytic activity of ascorbic acid was also investigated since it is a renowned antioxidant compound by the scientific community. The $\mathrm{IC}_{50}$ value calculated for ascorbic acid after $3 \mathrm{~h}$ of incubation was found to be $31.0 \pm 5.6 \mu \mathrm{g} / \mathrm{ml}$. Comparison of results based on inhibitory efficiency shown statistically significant differences $(P<0.05)$ between propolis extracts and ascorbic acid. Moreover, the antioxidant effect of propolis observed in this study was higher than or comparable to that of green tea extract reported previously by Costa et al. (2009) in the same experimental conditions. It is therefore evidenced that Portuguese propolis is a powerful antioxidant agent and may be used as a preventive medicine against oxidative stress and damage to cellular molecules and membranes, thus maintaining structural and functional integrity of the cells.

The antioxidant properties of propolis extracts are certainly related to its chemical composition. Many studies have evidenced the presence of flavonoids (including flavones, flavonols, flavanones and dihydroflavonols) and other phenolics (mainly substituted cinnamic acids and their esters) as main active constituents of propolis possessing potent antioxidant activities (Moreno, 2000; Kumazawa et al., 2004; Banskota et al., 2001b). The samples of the present study were previously characterized by Moreira et al. (2008) and, more recently, by Falcão et al. (2010). It was shown that Portuguese propolis samples (from Bornes and Fundão regions) contain considerable amounts of polyphenolic compounds and possess effective DPPH radical scavenging and reducing activities. In addition, Falcão et al. (2010) reported for the first time the phenolic profile of the
Northeast Portuguese propolis (from Bornes region). The most abundant compounds in this matrix were those commonly found in the phenolic extracts of propolis from temperate zones (Gardana et al., 2007; Marcucci, 1995): it contained phenolic acids, including caffeic, p-coumaric, ferulic and isoferulic acids, and their esters, such as the caffeic acid benzyl ester, the caffeic acid phenylethyl ester (CAPE), the caffeic acid isoprenyl ester and its isomer, and the caffeic acid cinnamyl ester. In addition, flavonoids previously described in propolis were also detected in the Portuguese sample, i.e., dihydroflavonols, flavones, flavanones, and flavonols, either as free form or their methylated/esterified forms. In particular, it was present the aglycones forms of apigenin, pinobanksin, pinocembrin and chrysin, the esterified derivatives pinobanksin-3-O-acetate, pinobanksin-3-O-propionate, pinobanksin-3-O-butyrate or isobutyrate and pinobanksin3-O-pentanoate or 2-methylbutyrate, and the methylated derivatives pinobanksin-5-methyl-ether, pinocembrin-5-methyl-ether, chrysin-5-methyl-ether, and chrysin-6-methyl-ether (Falcão et al., 2010). While the propolis sample from Bornes region has already been extensively characterized, the phenolic profile of propolis from Fundão region remains unknown, but there is no reason to believe that the main phenolic constituents are significantly different between the two samples. Work is currently in progress to confirm the chemical characterization of Fundão propolis.

Polyphenolic compounds have been found to protect erythrocytes from oxidative stress or increase their resistance to damage caused by oxidants (Kaviarasan et al., 2004; Asgary et al., 2005; Biswas et al., 2005). They are able to act as antioxidants in a num- 
ber of ways, mainly as reducing agents, hydrogen donors, singlet oxygen quenchers, and metal chelating agents (Cao et al., 1997; Rice-Evans et al., 1996). Therefore, propolis polyphenols present in the incubation medium may quench peroxyl radicals in the aqueous phase before the radicals attack the biomolecules of the erythrocyte membrane to cause peroxidation and, ultimately, hemolysis.

\subsection{Portuguese propolis selectively inhibits the in vitro proliferation of human RCC}

Renal cell carcinoma (RCC) is the most lethal urologic cancer. Symptoms arise late in the course of disease, hence approximately $50 \%$ of patients present with locally advanced or metastatic disease and have poor prognosis due to the high resistance of RCC to current chemotherapy and radiotherapy regimens (Motzer et al., 2000). Therefore, the discovery of new strategies for therapeutic intervention remains a priority. In this regard, natural products have been largely explored over the past decades since they are expected to play an important role in creating new and effective chemopreventive and therapeutic agents.

Propolis has been extensively studied for its anticancer potential. Inhibition of cell growth and the induction of apoptosis in different cancer cell lines by propolis and its polyphenols have been reported (Li et al., 2010; Sha et al., 2009; Usia et al., 2002). However, to the best of our knowledge, the anticarcinogenic effect of propolis in RCC cells has not been investigated yet. Therefore, the present study was designed to evaluate the growth inhibitory activity of extracts from Portuguese propolis in human RCC, using primary cultures of malignant renal cells and A-498 cell line. Of major importance to our study is that primary cell cultures isolated from human kidney tissues were used, which have several distinct advantages over immortalized cell lines. The renal primary cell cultures retain many of phenotypic characteristics of the original tissue and, therefore, can be highly relevant models for pharmacological evaluation of sensitivity/toxicity and therapeutic responses. This in vitro model can theoretically predict in vivo responses to a specific agent. In addition, the use of multiple donors for samples of tissue to generate independent isolates of primary cells allows researchers to demonstrate consistent responses among individuals (Marshak and Greenwalt, 2006).

Selectivity is also an important issue in cancer prevention and therapy. Therefore, the cytotoxic effect of propolis extracts in human normal renal cells was also evaluated. The in vitro cytotoxic and antiproliferative activities were determined using the MTT assay. Fig. 3 presents the concentration effectiveness of propolis extracts on the viability of primary cultured normal and cancerous renal cells, and A-498 renal cancer cell line. Four different concentrations of each extract $(10,25,50$, and $100 \mu \mathrm{g} / \mathrm{ml})$ were tested. Panel A shows that propolis extracts are weakly toxic to human normal renal cells. In contrast, Fundão and Bornes propolis extracts strongly and equally supressed the proliferation of primary renal cancerous cells in a concentration-dependent manner, with 91 and $85 \%$ cell growth inhibition at a concentration level of $100 \mu \mathrm{g}$ of extract/ml (Fig. 3, Panel B). The $\mathrm{IC}_{50}$ values calculated for Fundão and Bornes propolis in primary renal neoplastic cells were $56.5 \pm 16.7$ and $56.1 \pm 20.9 \mu \mathrm{g}$ of extract $/ \mathrm{ml}$, respectively. However, in A-498 cell line, Bornes propolis extract exerted higher antiproliferative activity than Fundão propolis (Fig. 3, Panel C). $\mathrm{IC}_{50}$ value obtained for Bornes propolis was $70.8 \pm 10.7 \mu \mathrm{g}$ of extract $/ \mathrm{ml}$, while for Fundão sample it was $>100 \mu \mathrm{g}$ of extract $/ \mathrm{ml}$. The different results obtained between Bornes and Fundão propolis are likely to be explained by the higher amount of phenolic compounds present in Bornes propolis (Moreira et al., 2008).

The inhibitory effect against renal cancer cell growth exhibited by these propolis samples may be related to an overall effect of the phenolic compounds present in the extracts, being caffeic acid, caffeic acid phenethyl ester (CAPE), quercetin, chrysin, apigenin, kaempferol, kaempferid, and galangin the most promising as antitumor agents (Orsolić et al., 2005). The antiproliferative activity of flavonoids, as well as that of hydroxycinnamic acids, on several cancer cell lines is widely reported in the literature (Patel et al., 2007; Marcucci, 1995; Li et al., 2008; Chen et al., 2004; Fresco et al., 2006; Kawaii et al., 1999; Bankova, 2005). Among them, CAPE has been identified as a major anticancer compound in European propolis (Banskota et al., 2002). It has been reported that human cancer cell lines displayed a significantly greater sensitivity to the action of CAPE than analogous normal lines (Chiao et al., 1995; Frenkel et al., 1993), which is in accordance with the cancer cell-selective toxicity exhibited by propolis extracts in the present study. The antitumoral activity of benzyl, phenethyl and cinnamyl caffeates isolated from propolis samples was reported (Banskota et al., 2002; Jin et al., 2005; Usia et al., 2002). However, other components present in propolis, such as terpenoids and waxy acids, may also exhibit inhibitory actions on cancer cell growth. For example, Pratsinis et al. (2010) showed that manool, a diterpene isolated from Greek propolis, was the most cytotoxic compound against HT-29 human colon adenocarcinoma cells. Therefore, the anticancer activity of propolis may be attributed to a synergism between phenolic and other constituents in the resin, rather than to the effect of a specific phytochemical or a class of phytochemicals.

The present study shows, for the first time, that propolis extract markedly prevented the proliferation of human RCC cells in vitro. However, the molecular mechanisms for these anticancer actions are not fully understood. As referred before, phenolic compounds present in propolis are known to possess antioxidant properties, and these properties may play a key role in the anticancer activities. It has been suggested that antiproliferative activities of caffeic acid derivatives (mainly CAPE) present in propolis may be related to its modulation of oxidative processes in cells (Banskota et al., 2002; Usia et al., 2002). However, the antioxidant properties of these phenolic compounds may not entirely explain their chemopreventive effects. Recent studies showed that CAPE inhibits the proliferation of hepatocarcinoma cell lines Hep3B and SK-Hep1 through inhibition of matrix metalloproteinase (MMP)-2 and MMP-9 activity (Lee et al., 2008; Jin et al., 2005). MMPs are a family of zinc-dependent neutral endopeptidases that elicit degradation of the extracellular matrix and basement membranes, ultimately leading to tumoral progression. Other mechanisms include inhibition of angiogenesis (Kunimasa et al., 2009) and metastasis (Hwang et al., 2006), cell-cycle arrest (Pratsinis et al., 2010), and induction of growth arrest and apoptosis through regulation of multiple signaling pathways (Chen et al., 2004; Bufalo et al., 2010; Fresco et al., 2006; Orsolić et al., 2005).

In conclusion, this work presents the first report on the biological activities of Portuguese propolis. Using human erythrocytes as a cellular model, we demonstrated that propolis extracts at very low concentrations can inhibit or reduce lipid peroxidation and hemolysis induced by peroxyl radicals. In addition, the results of this study represent the first evidence that propolis displays effective antiproliferative activity against human renal cancer cells. Furthermore, the comparison of the in vitro responses of normal and malignant cells to propolis extracts revealed that cancerous cells were more sensitive in terms of growth inhibition than normal cells. Overall, these findings support Portuguese propolis as a promising therapeutic agent in the prevention of diseases mediated by free radicals and particularly in the chemoprevention of RCC. Additional studies in animal models and clinical trials are required to fully evaluate the potential of propolis in the prevention and/or treatment of kidney cancer. 

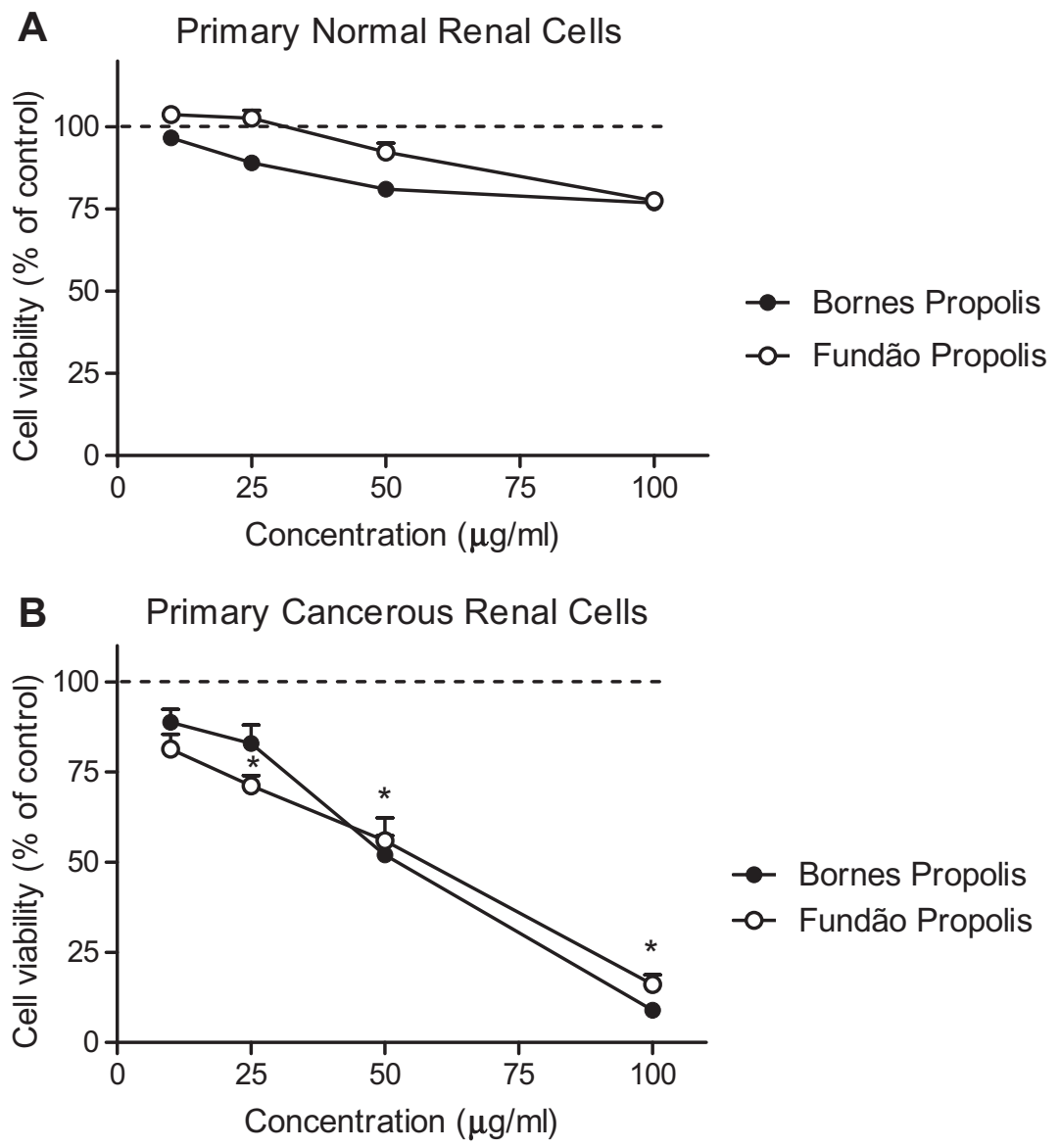

C A-498 Cancer Cell Line

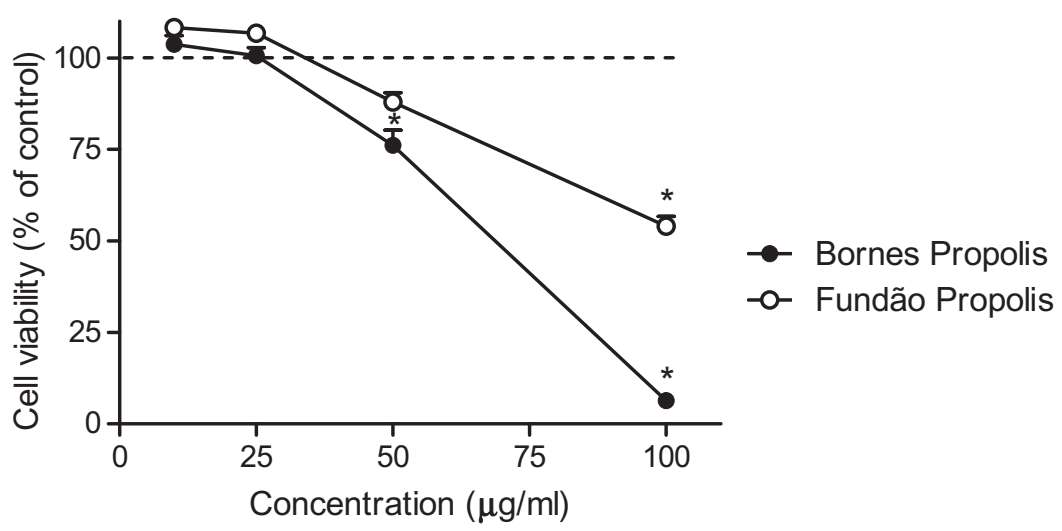

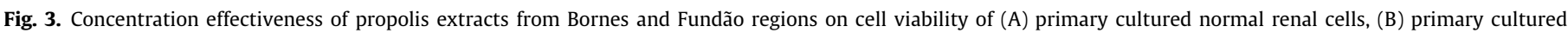

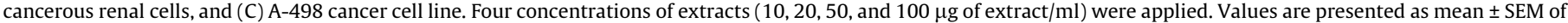
three independent experiments performed in quadruplicate. * Represents significant results $(P<0.05)$ when the treated group was compared with the control group.

\section{Conflict of Interest}

The authors declare that there are no conflicts of interest.

\section{References}

Asgary, S., Naderi, G., Askari, N., 2005. Protective effect of flavonoids against red blood cell hemolysis by free radicals. Exp. Clin. Cardiol. 10, 88-90.

Awale, S., Li, F., Onozuka, H., Esumi, H., Tezuka, Y., Kadota, S., 2008. Constituents of Brazilian red propolis and their preferential cytotoxic activity against human pancreatic PANC-1 cancer cell line in nutrient-deprived condition. Bioorg. Med. Chem. 16, 181-189.

Bankova, V., 2005. Chemical diversity of propolis and the problem of standardization. J. Ethnopharmacol. 100, 114-117.
Banskota, A.H., Nagaoka, T., Sumioka, L.Y., Tezuka, Y., Awale, S., Midorikawa, K., Matsushige, K., Kadota, S., 2002. Antiproliferative activity of the Netherlands propolis and its active principles in cancer cell lines. J. Ethnopharmacol. 80, 6773.

Banskota, A.H., Tezuka, Y., Adnyana, I.K., Ishii, E., Midorikawa, K., Matsushige, K., Kadota, S., 2001a. Hepatoprotective and anti-Helicobacter pylori activities of constituents from Brazilian propolis. Phytomedicine 8, 16-23.

Banskota, A.H., Tezuka, Y., Adnyana, I.K., Midorikawa, K., Matsushige, K., Message, D., Huertas, A.A., Kadota, S., 2000. Cytotoxic, hepatoprotective and free radical scavenging effects of propolis from Brazil, Peru, the Netherlands and China. J. Ethnopharmacol. 72, 239-246.

Banskota, A.H., Tezuka, Y., Kadota, S., 2001b. Recent progress in pharmacological research of propolis. Phytother. Res. 15, 561-571.

Biswas, S., Bhattacharyya, J., Dutta, A.G., 2005. Oxidant induced injury of erythrocyte-role of green tea leaf and ascorbic acid. Mol. Cell. Biochem. 276, 205-210. 
Bufalo, M.C., Candeias, J.M., Sousa, J.P., Bastos, J.K., Sforcin, J.M., 2010. In vitro cytotoxic activity of Baccharis dracunculifolia and propolis against HEp-2 cells. Nat. Prod. Res..

Burdock, G.A., 1998. Review of the biological properties and toxicity of bee propolis (propolis). Food Chem. Toxicol. 36, 347-363.

Cao, G., Sofic, E., Prior, R.L., 1997. Antioxidant and prooxidant behavior of flavonoids: structure-activity relationships. Free Radic. Biol. Med. 22, 749-760.

Carvalho, M., Hawksworth, G., Milhazes, N., Borges, F., Monks, T.J., Fernandes, E., Carvalho, F., Bastos, M.L., 2002. Role of metabolites in MDMA (ecstasy)-induced nephrotoxicity: an in vitro study using rat and human renal proximal tubular cells. Arch. Toxicol. 76, 581-588.

Carvalho, M., Ferreira, P.J., Mendes, V.S., Silva, R., Pereira, J.A., Jerónimo, C., Silva, B.M., 2010. Human cancer cell antiproliferative and antioxidant activities of Juglans regia L.. Food Chem. Toxicol. 48, 441-447.

Chen, C., Weng, M., Wu, C., Lin, J., 2004. Comparison of radical scavenging activity, cytotoxic effects and apoptosis induction in human melanoma cells by taiwanese propolis from different sources. Evid. Based Complement. Alternat. Med. 1, 175-185.

Chiao, C., Carothers, A.M., Grunberger, D., Solomon, G., Preston, G.A., Barrett, J.C. 1995. Apoptosis and altered redox state induced by caffeic acid phenethyl ester (CAPE) in transformed rat fibroblast cells. Cancer Res. 55, 3576-3583.

Costa, R.M., Magalhães, A.S., Pereira, J.A., Andrade, P.B., Valentão, P., Carvalho, M. Silva, B.M., 2009. Evaluation of free radical scavenging and antihemolytic activities of quince (Cydonia oblonga) leaf: a comparative study with green tea (Camellia sinensis). Food Chem. Toxicol. 47, 860-865.

Esterbauer, H., Schaur, R.J., Zollner, H., 1991. Chemistry and biochemistry of 4hydroxynonenal, malonaldehyde and related aldehydes. Free Rad. Biol. Med. 11, 81-128.

Falcão, S.I., Vilas-Boas, M., Estevinho, L.M., Barros, C., Domingues, M.R., Cardoso, S.M., 2010. Phenolic characterization of Northeast Portuguese propolis: usual and unusual compounds. Anal. Bioanal. Chem. 396, 887-897.

Frenkel, K., Wei, H., Bhimani, R., Ye, J., Zadunaisky, J.A., Huang, M.T., Ferraro, T., Conney, A.H., Grunberger, D., 1993. Inhibition of tumor promoter-mediated processes in mouse skin and bovine lens by caffeic acid phenethyl ester. Cancer Res. 53, 1255-1261.

Fresco, P., Borges, F., Diniz, C., Marques, M.P., 2006. New insights on the anticancer properties of dietary polyphenols. Med. Res. Rev. 26, 747-766.

Gardana, C., Scaglianti, M., Pietta, P., Simonetti, P., 2007. Analysis of the polyphenolic fraction of propolis from different sources by liquid chromatography-tandem mass spectrometry. J. Pharm. Biomed. Anal. 45, 390-399.

Hwang, H.J., Park, H.J., Chung, H., Min, H., Park, E., Hong, J., Lee, S.K., 2006. Inhibitory effects of caffeic acid phenethyl ester on cancer cell metastasis mediated by the down-regulation of matrix metalloproteinase expression in human HT1080 fibrosarcoma cells. J. Nutr. Biochem. 17, 356-362.

Ishihara, M., Naoi, K., Hashita, M., Itoh, Y., Suzui, M., 2009. Growth inhibitory activity of ethanol extracts of Chinese and Brazilian propolis in four human colon carcinoma cell lines. Oncol. Rep. 22, 349-354.

Izuta, H., Narahara, Y., Shimazawa, M., Mishima, S., Kondo, S., Hara, H., 2009. 1,1Diphenyl-2-picrylhydrazyl radical scavenging activity of bee products and their constituents determined by ESR. Biol. Pharm. Bull. 32, 1947-1951.

Jin, U., Chung, T., Kang, S., Suh, S., Kim, J., Chung, K., Gu, Y., Suzuki, I., Kim, C., 2005. Caffeic acid phenyl ester in propolis is a strong inhibitor of matrix metalloproteinase-9 and invasion inhibitor: isolation and identification. Clin. Chim. Acta 362, 57-64.

Kaviarasan, S., Vijayalakshmi, K., Anuradha, C., 2004. Polyphenol-rich extract of fenugreek seeds protect erythrocytes from oxidative damage. Plant Foods Hum. Nutr. 59, 143-147.

Kawaii, S., Tomono, Y., Katase, E., Ogawa, K., Yano, M., 1999. Antiproliferative activity of flavonoids on several cancer cell lines. Biosci. Biotechnol. Biochem. 63, 896-899.

Ko, F.N., Hsiao, G., Kuo, Y.H., 1997. Protection of oxidative hemolysis by demethyldiisoeugenol in normal and beta-thalassemic red blood cells. Free Rad. Biol. Med. 22, 215-222.

Kumazawa, S., Hamasaka, T., Nakayama, T., 2004. Antioxidant activity of propolis of various geographic origins. Food Chem. 84, 329-339.

Kunimasa, K., Ahn, M.R., Kobayashi, T., Eguchi, R., Kumazawa, S., Fujimori, Y., Nakano, T., Nakayama, T., Kaji, K., Ohta, T., 2009. Brazilian Propolis Suppresses Angiogenesis by Inducing Apoptosis in Tube-forming Endothelial Cells through Inactivation of Survival Signal ERK1/2. Evid. Based Complement. Alternat. Med. $1-7$

Lee, K.W., Kang, N.J., Kim, J.H., Lee, K.M., Lee, D.E., Hur, H.J., Lee, H.J., 2008. Caffeic acid phenethyl ester inhibits invasion and expression of matrix metalloproteinase in SK-Hep1 human hepatocellular carcinoma cells by targeting nuclear factor kappa B. Genes Nutr. 2, 319-322.

Li, F., Awale, S., Tezuka, Y., Esumi, H., Kadota, S., 2010. Study on the constituents of Mexican propolis and their cytotoxic activity against PANC-1 human pancreatic cancer cells. J. Nat. Prod. 73, 623-627.

Li, F., Awale, S., Tezuka, Y., Kadota, S., 2008. Cytotoxic constituents from Brazilian red propolis and their structure-activity relationship. Bioorg. Med. Chem. 16, 5434-5440.

Libério, S.A., Pereira, A.L., Araújo, M.J., Dutra, R.P., Nascimento, F.R., Monteiro-Neto, V., Ribeiro, M.N., Gonçalves, A.G., Guerra, R.N., 2009. The potential use of propolis as a cariostatic agent and its actions on mutans group streptococci. J. Ethnopharmacol. 125, 1-9.

Marcucci, M.C., 1995. Propolis: chemical composition, biological properties and therapeutic activity. Apidologie 26, 83-99.

Marshak, D.R., Greenwalt, D.E., 2006. Differentiating primary human cells in rapidthroughput discovery applications. In: Taylor, D., Haskins, J., Giuliano, A. (Eds.) High Content Screening: A Powerful Approach to Systems Cell Biology and Drug Discovery. Humana Press, New Jersey, pp. 121-128.

Moreira, L., Dias, L.G., Pereira, J.A., Estevinho, L., 2008. Antioxidant properties, total phenols and pollen analysis of propolis samples from Portugal. Food Chem. Toxicol. 46, 3482-3485.

Moreno, M., 2000. Comparison of the free radical-scavenging activity of propolis from several regions of Argentina. J. Ethnopharmacol. 71, 109-114.

Motzer, R.J., Mazumdar, M., Bacik, J., Russo, P., Berg, W.J., Metz, E.M., 2000. Effect of cytokine therapy on survival for patients with advanced renal cell carcinoma. J. Clin. Oncol. 18, 1928-1935.

Orsolić, N., Saranović, A.B., Basić, I., 2006. Direct and indirect mechanism(s) of antitumour activity of propolis and its polyphenolic compounds. Planta Med. 72, 20-27.

Orsolić, N., Terzić, S., Mihaljević, Z., Sver, L., Basić, I., 2005. Effects of local administration of propolis and its polyphenolic compounds on tumor formation and growth. Biol. Pharm. Bull. 28, 1928-1933.

Patel, D., Shukla, S., Gupta, S., 2007. Apigenin and cancer chemoprevention: progress, potential and promise. Int. J. Oncol. 30, 233-245.

Perron, N.R., Brumaghim, J.L., 2009. A review of the antioxidant mechanisms of polyphenol compounds related to iron binding. Cell Biochem. Biophys. 53, 75100.

Pratsinis, H., Kletsas, D., Melliou, E., Chinou, I., 2010. Antiproliferative activity of Greek propolis. J. Med. Food 13, 286-290.

Rice-Evans, C., 2001. Flavonoid antioxidants. Curr. Med. Chem. 8, 797-807.

Rice-Evans, C., Miller, N., Paganga, G., 1996. Structure-antioxidant activity relationships of flavonoids and phenolic acids. Free Rad. Biol. Med. 20, 933-956.

Russo, A., Cardile, V., Sanchez, F., Troncoso, N., Vanella, A., Garbarino, J.A., 2004 Chilean propolis: antioxidant activity and antiproliferative action in human tumor cell lines. Life Sci. 76, 545-558.

Scazzocchio, F., D’Auria, F.D., Alessandrini, D., Pantanella, F., 2006. Multifactorial aspects of antimicrobial activity of propolis. Microbiol. Res. 161, 327-333.

Schnitzler, P., Neuner, A., Nolkemper, S., Zundel, C., Nowack, H., Sensch, K.H., Reichling, J., 2010. Antiviral activity and mode of action of propolis extracts and selected compounds. Phytother. Res. 24, S20-28.

Sforcin, J.M., 2007. Propolis and the immune system: a review. J. Ethnopharmacol $113,1-14$.

Sha, N., Guan, S., Lu, Z., Chen, G., Huang, H., Xie, F., Yue, Q., Liu, X., Guo, D., 2009 Cytotoxic constituents of Chinese propolis. J. Nat. Prod. 72, 799-801.

Silici, S., Koç, N.A., Ayangil, D., Çankaya, S., 2005. Antifungal activities of propolis collected by different races of honeybees against yeasts isolated from patients with superficial mycoses. J. Pharmacol. Sci. 99, 39-44.

Soares, M.E., Carvalho, M., Remião, F., Carvalho, F., Bastos, M., 2004. Implementation of HPLC methodology for the quantification of malondialdehyde in cell suspensions and liver. J. Liq. Chromatogr. Relat. Technol. 27, 2357-2369.

Tan-No, K., Nakajima, T., Shoji, T., Nakagawasai, O., Niijima, F., Ishikawa, M., Endo, Y., Sato, T., Satoh, S., Tadano, T., 2006. Anti-inflammatory effect of propolis through inhibition of nitric oxide production on carrageenin-induced mouse paw edema. Biol. Pharm. Bull. 29, 96-99.

Usia, T., Banskota, A.H., Tezuka, Y., Midorikawa, K., Matsushige, K., Kadota, S., 2002 Constituents of Chinese propolis and their antiproliferative activities. J. Nat Prod. 65, 673-676.

Weng, M., Liao, C., Chen, C., Wu, C., Lin, J., 2007. Propolin $\mathrm{H}$ from Taiwanese propolis induces G1 arrest in human lung carcinoma cells. J. Agric. Food Chem. 55, 52895298.

Zou, C.G., Agar, N.S., Jones, G.L., 2001. Oxidative insult to human red blood cells induced by free radical initiator AAPH and its inhibition by a commercial antioxidant mixture. Life Sci. 69, 75-86. 